\title{
REPRESENTAÇÕES DE INTELECTUAIS EM VENCIDOS E DEGENERADOS, DE NASCIMENTO MORAES ${ }^{1}$
}

\section{INTELLECTUALS' REPRESENTATIONS IN DEFEATED AND DEGENERATED, OF NASCIMENTO DE MORAES}

\author{
DORVAL DO NASCIMENTO \\ Prof. Dr. da Universidade Federal do Maranhão/ PPGH-UFMA \\ Bolsista produtividade da FAPEMA \\ São Luís/Maranhão/Brasil \\ dorval@ufma.br
}

\begin{abstract}
Resumo: Análise das representações de intelectuais no romance-crônica de José do Nascimento Moraes, publicado em 1915. Busca-se investigar as vicissitudes da condição intelectual em um campo literário periférico, no caso, o maranhense da Primeira República, em especial, as condições de exercício da atividade intelectual, possibilidades de sobrevivência e relações entre o campo literário e o campo político. Nascimento Moraes foi um polígrafo com atuação intensa no âmbito regional e que se caracterizou por militar na oposição durante a maior parte da Primeira República. Sua peculiar abordagem dos processos e agentes sociais, oriunda de sua posição subalternizada, pode oferecer pontos de vista que iluminem as relações sociais e políticas a que estavam sujeitos os intelectuais maranhenses naquele período histórico. Pretende-se explorar as possibilidades que o texto literário oferece, no caso, o romance-crônica Vencidos e Degenerados, para a compreensão da temporalidade pretérita.
\end{abstract}

Palavras-chave: Intelectuais, Literatura, Maranhão, Primeira República.

Abstract: Analysis of the intellectual representations in the chronicle-romance of José do Nascimento Morais, published in 1915. Intend to investigate the vicissitudes of the intellectual conditions in a peripheral literary field, such as the Maranhão in the First Republic, in particular the performance conditions of the intellectual activity, survival possibilities and the relationship between the literary and political fields. Nascimento Moraes was a polygraph with intense regional activity that was characterized as military in the resistance during the most of the First Republic. His peculiar approach of the processes and social agents, arising from his subaltern position, may offer point of views which can enlighten the social and political relationships that were connected with the Maranhão's intellectuals in that period of time. Intend to explore the possibilities that the literary text offers, in this case the chronicle-romance Vencidos e Degenerados, in the comprehension of the preterit temporality.

Keywords: Intelectuals, Literature, Maranhão, Firs Republic.

${ }^{1}$ Artigo submetido à avaliação em 09 /08/2012 e aprovado para publicação em 28/10 /2012. 
A intenção deste texto é compreender as condições do exercício da carreira intelectual na Primeira República, em São Luís/MA, a partir de representações de intelectuais presentes no texto literário Vencidos e Degenerados - Crônica Maranhense (MORAES, 2000), de autoria de José do Nascimento Moraes, publicado pela primeira vez em 1915. A intenção é compreender as condições de atuação de intelectuais em um campo literário periférico, como era o caso do maranhense na Primeira República, em especial as possibilidades de sobrevivência e relações entre o campo literário e o campo político.

Opero com o conceito de campo intelectual na perspectiva de Bourdieu: como um espaço social específico de relações dinâmicas em que os agentes se posicionam, influenciando-se reciprocamente e sendo influenciados pelas relações em seu conjunto.

\footnotetext{
Minha hipótese consiste em supor que, entre esses dois pólos [conteúdo textual e contexto social], muito distanciados, entre os quais se supõe, um pouco imprudentemente, que a ligação possa se fazer, existe um universo intermediário que chamo o campo literário, artístico, jurídico ou científico, isto é, o universo no qual estão inseridos os agentes e as instituições que produzem, reproduzem ou difundem a arte, a literatura ou a ciência. Esse universo é um mundo social como os outros, mas obedece a leis sociais mais ou menos específicas (BOURDIEU, 2004, p. 20).
}

Ainda que não seja possível comparar as atividades intelectuais no Maranhão da Primeira República com os processos de autonomização do campo literário francês em fins do século XIX, tais como analisados por Bourdieu (2010), o conceito de campo, no entanto, permite localizar o universo social no qual se moviam os agentes que lidavam com literatura naquele período e investigar, desta forma, suas condições de atuação. Em que pese as restrições de diferentes autores (PÉCAUT, 1990) quanto à utilização do conceito para caracterizar as relações intelectuais e literárias no século XX no Brasil, campo é, a meu ver, um conceito operatório que permite avaliar os homens de letras e intelectuais em um universo social mais próximo de suas relações sociais, culturais e simbólicas, escapando às armadilhas postas por análises relacionadas a termos como "sociedade", "contexto" ou "conjuntura".

A utilização de textos literários como indícios capazes de contribuir no trabalho do historiador para restituir a passeidade foi possibilitada pela ruptura do paradigma então dominante na historiografia e a emergência de novos objetos e, por decorrência, o uso de novas fontes capazes de permitir ao pesquisador o acesso a questões até então secundarizadas no ofício 
do historiador. Guardadas as diferenças de gênero e função, história e literatura são narrativas que têm o real como referente e operam com representações que se referem à vida e que buscam explicá-la (PESAVENTO, 2006, p.2). Ainda que remeta ao não-acontecido, o texto literário dialoga com a temporalidade presente de sua escrita e, desta forma, propicia ao historiador o acesso àquela sociedade que o produziu:

\begin{abstract}
A sintonia fina de uma época, fornecendo uma leitura do presente da escrita, pode ser encontrada em um Balzac ou em um Machado, sem que nos preocupemos com o fato de Capitu, ou do Tio Goriot e de Eugène de Rastignac, terem existido ou não. Existiram enquanto possibilidades, como perfis que retraçam sensibilidades. Foram reais na 'verdade do simbólico' que expressam, não no acontecer da vida. São dotados de realidade porque encarnam defeitos e virtudes dos humanos, porque nos falam do absurdo da existência, das misérias, das conquistas gratificantes da vida. Porque falam das coisas para além da moral e das normas, para além do confessável, por exemplo (PESAVENTO, 2006, p.3).
\end{abstract}

Portanto, o uso do texto literário como indício não opera a partir de uma dicotomia fechada entre o mundo do texto e o mundo exterior ao texto, um imaginário e outro real, mas se busca perceber como aquela sociedade passada configurou-se e foi reconfigurada para/pelo autor que, através de sua atividade criativa, conformou o mundo do texto, relativamente autônomo por certo, mas assentado na época e na sociedade em que o autor vivia e atuava, temporalidade a que o historiador tem acesso, também relativo, a partir do texto produzido.

O autor cuja narrativa se discutirá neste trabalho, nascido em 1882, estava a quatro dias de completar 33 anos quando o texto foi publicado. Era um intelectual conhecido nos meios literários de São Luís, Maranhão, atuando principalmente na imprensa como cronista e polemista. Em uma nota de rodapé aposta à apresentação do romance na edição que estamos trabalhando, apresentação escrita pelo autor, informa-se que o romance encontrava-se pronto desde 1913, dois anos antes de sua publicação (MORAES, 2000ㄹ, p. 298). O autor, no entanto, na referida apresentação, afirma que o escreveu "nos meus primeiros anos de vida literária, quando se me rasgavam as primeiras linhas do horizonte, quando sentia as primeiras impressões. Quantos anos passados!...” (p. 297), dando a entender que o texto fora escrito muito tempo antes.

Fixar o tempo da escrita do texto parece-me fundamental para sua correta utilização como indício da passeidade. Neste caso, avento a hipótese de que a principal parte do texto, senão todo, tenha sido escrita antes de 1910. Essa possibilidade decorre das características da condição intelectual tal como formulada no texto literário, como veremos, em conexão com a situação do 
autor no campo intelectual regional neste período. Sabemos que a morte de Benedito Leite, em 1909 - oligarca que havia estabilizado o sistema regional de dominação no princípio da Primeira República -, detonou uma crise política que foi resolvida por um acordo entre as diferentes facções oligárquicas e o presidente Nilo Peçanha. O resultado foi a ascensão de Luiz Domingues (1910-1914) e Herculano Parga (1914-1918) ao governo estadual, políticos que não tinham relações tão íntimas com as frações dominantes da oligarquia e que tentaram uma linha de fortalecimento próprio (REIS, 1992, p.58). Essa opção política implicou no concurso de intelectuais para a defesa do mandatário estadual, em um campo intelectual frágil e dependente das demandas do campo político (NASCIMENTO, 2011), o que significou melhores possibilidades de atuação para Nascimento Moraes, como se depreende de sua biografia. De fato, ao se referir a José do Nascimento Moraes, Nauro Machado afirma que Benedito Leite (1906-1908), Urbano Santos (1918-1922) e Raul Machado (1922-1923) foram os governadores mais combatidos por Moraes, o que pressupõe uma relação de proximidade com Domingues e Parga (MACHADO, 1982, p.10). Ao lançar seu principal texto literário, Nascimento Moraes o dedica "ao Dr. Luiz Domingues", o que corrobora a informação de sua aproximação com os mandatários estaduais naquele período. Desta forma, a se levar em conta esses dados, é possível estabelecer o tempo da escrita como estando situado na primeira década do século XX.

O romance trata da trajetória de Cláudio Olivier, que procura ascender socialmente em sua terra natal, São Luís/MA, através das letras. Cláudio era filho dos ex-escravos Domingos Daniel Aranha e Andreza Vidal, a última libertada por ocasião da lei de 1888, marco inicial do romance. Cláudio, no entanto, foi assumido como filho por João Olivier, mestiço que "se colocara na imprensa e se fizera guarda-livros de importante casa comercial" (p.28). O romance trata das vicissitudes de Cláudio, que tenta por diversos meios consagrar-se como intelectual e entrar para a sociedade local. Dentre essas estratégias de ascensão, destaca-se a fundação de um grêmio literário, destruído pela oposição das elites locais, e a tentativa de casamento com Amélia Rodrigues, filha de um membro da elite política, que acaba não se concretizando em vista de que o pai da moça, major Rodrigues, "espalha aos quatro ventos que só casará as filhas com portugueses ricos, ou homens formados" (p.187). Vencido diante das barreiras intransponíveis à sua ascensão, Cláudio deixa a cidade e retorna a ela por ocasião de uma sessão magna no Teatro São Luís, em comemoração ao aniversário da Proclamação da República (p. 277), local onde estavam reunidos os principais membros da sociedade ludovicense. Vinha do Amazonas com 
destino ao sul. O Cláudio que voltara, no dizer do narrador, não era "um Cláudio qualquer, pobretão, obscuro", mas "voltava rico, orgulhoso, abarrotado de brilhantes, comissionado pelo governo" (p.281). Vencera, enfim, mas longe de sua província e ao custo de deixar para trás seus amigos vencidos. O romance termina com Cláudio sabendo dos últimos dias do velho Carlos Bento Pereira, doente e esquecido, mestre e amigo de seu pai, João Olivier, e de si próprio. Ele então "abafou duas lágrimas traidoras que tinham corrido como duas mensageiras vindas do seu peito para lhe atestarem que lá dentro a dor antiga vivia silenciosa e esquecida, esmagada pela boa fortuna daqueles dias que desfrutara..." (p.296).

O romance caracteriza-se, quanto à forma narrativa, pela sua proximidade com a crônica, termo presente no subtítulo da obra. Não há propriamente densidade psicológica dos personagens ou descrição densa de ambientes, situações e relações, mas a colocação dos personagens em situações cotidianas, a partir das quais a narrativa se desenvolve. Assim, para sustentar a trama, o autor convoca uma plêiade de novos personagens que adentram a narrativa em profusão, sem que necessariamente, e quase nunca, se integrem organicamente ao centro da trama, que é a possibilidade e dificuldade de ascensão do personagem principal através do exercício das letras em uma sociedade hierarquicamente estruturada. A maior parte desses personagens é caracterizada como intelectuais, através do uso de vários termos como "homens de letras", "literatos", "poetas", "escritores" e "polígrafos". Em vista disso, optei por seguir os passos do personagem principal e, secundariamente, do velho Bento, como atores a partir dos quais é possível perceber a forma como o autor concebia o exercício intelectual na São Luís daquele período.

A opção - ou o limite - do autor em conceber seu romance como crônica permite-nos perceber um aspecto central na condição intelectual local na Primeira República: a atuação dos intelectuais na imprensa como a dimensão mais importante de sua condição. Nascimento Moraes trz para seu texto sua própria condição de homem de imprensa, que se caracterizaria fundamentalmente por ser cronista e polemista. Quando José Maria Maranhense, no início do romance, saúda João Olivier, designa-o pela expressão "ilustradíssimo causeur" (p. 28). A palavra causeur, de difícil tradução para o português, significaria aquele que fala, que se pronuncia, portanto, que se posiciona em relação aos acontecimentos cotidianos do lugar, daí o cronista, ou em relação à opinião pública, caracterizando o polemista. Olivier é um causeur ilustradíssimo porque, na opinião de Maranhense, utiliza a palavra com maestria em 
acontecimentos públicos, por exemplo, no caso da comemoração da abolição da escravidão na abertura do romance, ao se dirigir ao público presente, ou através de sua coluna no jornal local. $\mathrm{O}$ intelectual, tal como o apresenta o narrador, necessitaria, desta forma, ser um exímio esgrimista da palavra para exercê-la nos acontecimentos públicos e, mais ainda, na imprensa. A centralidade da atuação na imprensa e a representação do intelectual enquanto homem de imprensa pode ser percebido em uma fala de Olivier a respeito de Cláudio, ao tratar do tipo de formação que lhe estava proporcionando:

Quero o Cláudio um homem destemido e não um bacharel qualquer, forrado para resistir a insultos, pulso rigoroso para esmagar preconceitos; um polemista terrível que faça uma época e traga com a lâmina cortante de sua prosa, que há de ser castiça e fulgurante, o pêlo desses animais que nos maltratam. Se me educassem polemista, outros galos me cantariam, esse pessoal ruim passaria bem devagar em minhas mãos (p. 92).

Ademais, os jornais eram fundamentais, ao lado dos pronunciamentos políticos e literários em reuniões públicas ou privadas, para as estratégias de consagração desses intelectuais. A narrativa das repercussões, na imprensa local, do aniversário da filha de João Machado, personagem que ascendeu socialmente no decorrer da trama, permite-nos perceber que a posição da matéria no corpo do periódico e a forma como a notícia era formulada dava a ver a posição social do homenageado e, do mesmo modo, a orientação política e intelectual do jornal. No caso em questão, Cláudio observa que ocultaram propositadamente o nome do orador oficial da festa, o Dr. Álvares Rodrigues. É que ele, explica-nos o narrador, é “um moço de talento e de caráter inteiriço, aplicado a boas idéias e ações nobres, espírito disciplinado e independente" e que, por isso, "se não curvava à conveniência da roda, a que pertenciam os redatores do Diário, era preciso calar-lhe o nome, deitar sobre ele o manto pesadíssimo do esquecimento, para não ecoar a sua palavra, para não se pôr em foco o seu nome” (p. 179).

Estar na imprensa não significava, entretanto, viver dela, a não ser nos casos de revisor ou redator, e, mesmo assim, essas funções nem sempre eram remuneradas. Quando o narrador caracteriza o Cláudio adulto a partir dos olhos de seus adversários, afirma que ele "vivia de aulas particulares e de algumas escritas de quitanda" (p. 142), ainda que possuísse uma coluna no jornal denominada "rolhas e biscoitos" (p. 219). A imprensa era, entretanto, estratégica no contexto do campo intelectual maranhense naquele período no sentido que, através dela, a palavra do intelectual ecoava, seu nome aparecia e não caía sobre si o "manto pesadíssimo do 
esquecimento". Os periódicos eram, assim, mais utilizados para acumular capital simbólico do que para meios de vida, ainda que não se deva esquecer a possível conversão de um em outro (BOURDIEU, 2004).

Mas só estar na imprensa não bastava. Na terra de Gonçalves Dias, era preciso, além disso, ser homem de literatura. O tempo da escrita do romance, situado entre a abolição da escravidão e a primeira década republicana do século XX, aponta para a importância das produções de homens de letras no período e a atuação de intelectuais que são denominados pelas historiografia literária como novos atenienses. Publicar poesias e romances, fundar associações culturais e literárias, implicava em se vincular ao imaginário da Atenas Brasileira, e, através dele, a um período histórico em que o Maranhão inseriu-se com distinção no nascente Estado brasileiro pós-independência, afirmando esta distinção a partir de seus valores literários, em um momento em que a desaceleração do crescimento econômico se fazia sentir. Esse imaginário ecoava ainda um tempo memorizado como distinto daquele em que o texto narra, em que as condições sociais haviam propiciado o enriquecimento de alguns grupos sociais, o que permitiu um contato econômico e cultural mais estreito com a Europa, principalmente Portugal. Vincular-se a esse tempo como homens de letras era ligar-se a uma idade de ouro sempre lembrada e desejada, e que remetia a intelectuais consagrados como Gonçalves Dias e João Lisboa. Se as condições de enriquecimento haviam passado, restava a instância cultural como única capaz de fornecer verossimilhança a esse imaginário, o que abria possibilidades de ascensão, através das letras, para intelectuais como Cláudio, protagonista do romance, e Nascimento Moraes, seu autor.

Cláudio empreende, assim, uma ação estratégica fundamental para suas pretensões de ascensão por meio das letras em um espaço social dominado pelo imaginário, que se articulava a partir de certa representação do passado literário glorioso da província: fundou, com alguns colegas, o Grêmio Gonçalves Dias. Os jovens reuniam-se em sessões públicas em que um deles se responsabilizava pela defesa e discussão de uma tese; passaram a editar um pequeno periódico, O Campeão, que tinha o velho Bento como revisor, e a repercussão se fez quase imediata: “já lhes andava o nome por outras plagas e a imprensa de todo o país, por complacência ou não, elogiava-lhes os trabalhos" (p. 107). Cláudio fora mesmo chamado para "revisor e noticiarista do Jornal da Tarde, onde remuneravam os serviços com cinquenta mil réis mensais" (p. 107). "Em nome do Grêmio, já se apresentavam em muitas reuniões e faziam discursos em comícios populares" (p. 107). A tomada de posição de Cláudio e seus colegas desequilibrou, por assim 
dizer, as relações estabelecidas no campo intelectual instituído no romance. O narrador termina o episódio de fundação do Grêmio afirmando que "a coisa era séria. Aqueles rapazinhos com o tal clube iam longe. Muitas casas já lhes abriam as portas" (p. 107).

O empreendimento de Cláudio e seus colegas equivale, na narrativa, ao empreendimento de Nascimento Moraes ao lançar Vencidos e Degenerados. A diferença é que as condições de oposição ao grêmio, como veremos, eram muitíssimo mais intensas que as de recepção do romance. No período em que publicou o romance, em 1915, Moraes havia conseguido uma situação mais estável no campo literário local, pela aproximação com o governo estadual. É exatamente essa aproximação, a meu ver, que possibilita as condições financeiras e culturais que permitem a publicação da obra. Ainda que no campo literário regional a poesia estivesse no topo dos gêneros literários, e Gonçalves Dias era sempre lembrado, o lançamento de um romance, ainda mais por um intelectual subalterno naquelas relações estabelecidas, como era o caso de Moraes, significava um investimento fundamental para acumulação de capital simbólico e, com ele, outras possibilidades de acesso a postos mais importantes na estrutura governamental e na imprensa. Significava, também, nos dois casos, um desequilíbrio no campo intelectual local, o que implicava em oposição de outros homens de letras e seus aliados, na medida em que os recursos eram parcos e disputados com todas as armas que os contendentes dispunham.

A coisa era séria mesmo. Em um campo intelectual caracterizado no romance como frágil $^{2}$, com pouquíssimos postos de trabalho vinculados direta ou indiretamente às letras, a ascensão de um grupo de jovens no panorama literário da cidade atingia interesses estabelecidos de outros intelectuais. E não eram apenas jovens, mas também pobres. Pela apresentação de alguns personagens que formavam o grêmio, é possível perceber sua composição social: Plácido Monteiro, filho de um calafate; Júlio Bezerra, filho de uma mulher pobre, a engomar para sustentar o filho nos estudos (p. 104); Jorge da Cruz, neto de um desembargador que acabara pobre e deixara a família em completa pobreza (p. 106); Júlio Simas, telegrafista de quarta classe (p. 243), além de Cláudio, filho de ex-escravos e adotado por um jornalista que terminara seus dias na miséria. E mais: eram também negros ou mulatos, o que na sociedade maranhense construída pelo romance tinha a mesma implicação. Apenas Jorge é caracterizado como “um rapagote de cor branca" (p. 106). O leitor atento, e não qualquer leitor, fica assim avisado que tal empreendimento não poderia dar certo. Ao leitor desatento e a Cláudio, que talvez por sua juventude não tivesse clara a repercussão de seus atos e de seus amigos, o velho Bento, calejado 
nas disputas intelectuais da cidade, avisara: "Agora que você vai ver quem é esta gente... Prepare-se que eles para matar o Grêmio não trepidarão em jogar todas as armas: a calúnia, a intriga, mentira deslavada, falsos testemunhos..." (p. 217).

A reação não se fez por esperar, e ela permite perceber os recursos que se utilizavam nas disputas travadas no campo intelectual daquele período. Inicialmente, ridicularização e difamação. Os jovens não desistiram. Diante disso, alguns "rapazes da elite" ,como os caracteriza o narrador, fundaram o Clube Odorico Mendes e passaram a editar o jornal O Triunfo. Dentre os membros do novo clube, havia o filho do presidente da Câmara de uma cidade do interior, o sobrinho de um desembargador e o filho de um deputado estadual (p. 108). Ainda assim, não surtiu o efeito esperado. Utilizaram-se então expedientes diversos baseados no capital de relações sociais e poder de mando que possuíam os "rapazes da elite" e, principalmente, seus parentes. Cláudio é finalmente vencido. O grêmio é dissolvido. Ele explica assim sua derrota: "Resolvi acabar com a coisa antes que me sobrevenham outros males. Cada um deles [dos membros do grêmio] tem conveniências em não ofender os adversários... (...) se não resolvesse dissolver o grêmio, passaria pela decepção de me encontrar só, abandonado dos companheiros de lutas" (p. 253). Cláudio parece ter adquirido consciência de quanto era penoso desafiar os poderosos da terra, e essa consciência lhe será preciosa quando chegar a hora de se desvencilhar de suas relações pessoais na cidade e ir embora. Mas deixemo-lo um pouco mais em São Luís.

O episódio da fundação e dissolução do grêmio parece-me central no encaminhamento do enredo e na produção de significados da narrativa, a partir do que identifico como eixo central do romance a impossibilidade de intelectuais com as características de Cláudio, pobre e mulato, assumirem posições centrais no campo literário de São Luís da Primeira República, apesar dos supostos talentos que possuíssem. O narrador constrói dois corpos de literatos que se opõem, sobretudo, pela origem social e condição étnica. Em outras palavras, essas características socialmente estabelecidas são utilizadas como recursos nas disputas que se estabelecem no campo intelectual construído pela trama. Há, na narrativa desse episódio que se estende por muitas páginas, uma série de detalhes significativos que nos permite compreender a caracterização que o autor faz dos grupos em disputa e de seus lances simbólicos, a começar pelo título dos periódicos. O do grupo de Cláudio, em vista do caráter desafiador e desequilibrador de sua ação estratégica, tinha o título quase heroico de $O$ Campeão, enquanto o periódico dos “rapazes da elite" trazia o nome de $O$ Triunfo, a expressar não apenas o lugar social a partir de 
onde se pronunciavam, mas também a certeza que tinham, e com razão, de que no final da trama, efetivamente, seriam os vencedores, como sempre foram. O primeiro periódico foi lançado no dia 28 de julho (p. 106), data da adesão do Maranhão à independência do Brasil e, portanto, de derrota daqueles que tinham interesses na continuidade dos vínculos da província com Portugal, e que aparecem na narrativa como os senhores da situação da cidade, ou seja, os descendentes das famílias tradicionais e os comerciantes portugueses. O Clube dos "rapazes da elite" foi lançado no dia 15 de novembro, na sala nobre da Câmara Municipal e sob os auspícios de Odorico Mendes (p. 108), o redator do Argos da Lei, liberal e combatente contra os portugueses. A ironia e estupefação, elaboradoras de sentido, que o narrador quer produzir parecem óbvias ao leitor atento: o clube que representava as famílias e grupos sociais que dominavam a província desde há séculos tomava por patrono um liberal e era lançado na data comemorativa de um episódio histórico que, na visão do narrador, havia prometido exatamente acabar com o domínio desses grupos. O que denotava a capacidade das elites locais em se apropriarem de um episódio que havia, conforme deixa implícito o narrador, desencadeado esperanças de mudanças sociais que, posteriormente, se revelaram como ilusões.

A narrativa faz um balanço crítico e desiludido da abolição e da república, típico de diversos intelectuais daquela geração que haviam concluído que aqueles acontecimentos, apesar de despertar perspectivas de mudanças sociais, haviam consolidado antigos grupos no poder. Uma fala de João Olivier é representativa dessa perspectiva:

Quando se a liberdade dos escravos eu tinha a alma cheia de esperanças. Estava até certo ponto convencido de que nos bastaria dar um passo para atingirmos certo grau de prosperidade e começarmos a ser felizes. A Proclamação da República ainda mais esperanças me trouxe. Avigoraram-se-me as crenças e cheguei a sonhar com um Maranhão intelectualmente e moralmente livre, a ascender como um deus! Pois com tristeza lhe digo, bastou que transcorressem dois anos de vida republicana! Logo me persuadi de meu erro e exclamei, no desafogo de minha queixa ao ruir das minhas ilusões, como nosso querido Gonçalves Dias: - que me enganei, ora vejo! (p.76).

E conclui: "não foram verdadeiros republicanos os que se apossaram do poder..." (p.77). Não é coincidência que o autor escolheu os populares em festa no dia da abolição para abrir o romance e as elites em festa, no Teatro São Luís, comemorando a proclamação da República, para seu fechamento.

Bem que o velho Bento havia avisado a Cláudio: "agora que você vai ver quem é esta gente...”. Carlos Bento Pereira, o velho Bento, funciona no enredo como o exemplo do destino 
que aguardava Cláudio caso ele não entrasse na sociedade local e se decidisse por continuar na província. O narrador caracteriza-o como um dos "maiores poliglotas, uma das vastas ilustrações de que se honrava o Maranhão" (p. 74). Era jornalista e professor, mas estava afastado da imprensa em vista de lutas partidárias em que se envolvera e que o incompatibilizara com conservadores e liberais. Vivia de lecionar a particulares e das pequenas ofertas que lhe davam seus ex-discípulos, entre eles João Olivier. Estava a elaborar um panfleto, transcrito em boa parte pelo narrador, sobre a situação do Maranhão. No decorrer da narrativa, sua situação piora até o leitor encontrá-lo, no final, doente e abandonado por todos.

Percebe-se, na caracterização do personagem, o vínculo - e mesmo a dependência - que os intelectuais tinham em relação ao campo político. Fora por querer manter suas ideias próprias ou por falta de habilidade política - o narrador não nos diz - que Bento fora afastado da imprensa e começara seu calvário. Há, além disso, um episódio vinculado ao velho que nos ajuda a compreender um pouco melhor os políticos como formuladores de demandas que cabia aos intelectuais atenderem. Em um diálogo com Cláudio, o velho jornalista afirma que estava tratando da questão da carne verde (p. 202). "Por quem escreve?" - pergunta-lhe o jovem. "Pelos dois" - responde-lhe o velho e, diante de um espantado Cláudio, responde:

É simples: apareceu-me, em primeiro lugar, o Dr. Teodoro Ribas, interessado por parte do Sousa. Escrevi, pois, o primeiro artigo. Ao dia seguinte, apresenta-se-me cá o Moura Júnior e pede-me que responda ao artigo... Eu já não tinha dinheiro... Só a dívida da quitanda absorveu quase toda a quantia que me pagou o Ribas. O pedido do Moura veio tirar-me de outra dificuldade... Meti mãos à obra, eis-me a fazer polêmica comigo mesmo (p. 202).

Para além da astúcia do velho, percebe-se a dependência dos intelectuais em relação a uma imprensa partidária e, mesmo para os que estavam fora dela, a dependência das demandas que os políticos faziam em relação às questões em debate na cidade. Conquistar um nome respeitado, como era o caso de Bento, era imprescindível, mas não suficiente para garantir a sobrevivência. Imprescindível era também ser útil nas disputas políticas que se travavam entre os grupos oligárquicos do Estado. Essa utilidade própria do intelectual - o escrever e o falar - poderia lhe permitir, naquele período, acesso a atividades remuneradas na própria imprensa, como também acesso a funções públicas e a prebendas do Estado. Não esqueçamos que o Cláudio vitorioso e rico que retorna a São Luís no fim do romance era também "comissionado pelo governo" (p. 281). 
Mas permaneçamos com Cláudio na cidade mais um pouco. No dia seguinte ao baile na casa de João Machado, Cláudio esboça o desejo de casar-se com dona Amélia Rodrigues. O desejo não é apresentado pelo narrador como estratégia de ascensão, evidentemente, e nem como alternativa ao desmoronamento do grêmio, já que este ainda estava em pé, apesar de combalido. No entanto, os indícios apresentados nos fazem crer que Cláudio percebia que sua empreitada intelectual terminaria derrotada e, assim, o casamento era uma forma de alcançar nome e meios de vida por outras formas. Em suas reflexões, o enlace é pensado como uma possibilidade de abandonar o meio intelectual e suas disputas: "O Machado lhe arranjaria um emprego melhor, e ele alugaria uma morada inteira, em boa rua. Viveria modestamente, com sua mulher e os filhos, se os tivesse" (p. 181). Modéstia à parte, talvez de início, nem mesmo Cláudio poderia imaginar onde poderia terminar ao entrar para a família do major Rodrigues e, através dela, para a sociedade local. O sonho, no entanto, resistiu a apenas algumas páginas. Se a fundação do grêmio havia sido heroica, o sonho do casamento soa como patético. Entre a filha de uma das famílias tradicionais e o jovem sem condições financeiras e uma árvore genealógica "paupérrima e ínfima", como afirma, havia um imenso abismo, diante do qual Cláudio se vê obrigado a exclamar: "boa tarde, pensamento feliz!” (p. 188).

Cláudio finalmente fora vencido, o que remete ao título do romance. No texto, em apenas uma ocasião a expressão "degenerados e vencidos" é utilizada - assim mesmo, ao contrário do títul - pelo personagem Carmo, um dos intelectuais sem renome que participava das reuniões em casa de João da Moda (p. 125). Em todas as outras ocasiões em que a palavra "vencidos" aparece no texto, esta refere-se a intelectuais que não haviam alcançado consagração no campo intelectual regional, com uma única exceção (p. 271). Assim, se "vencidos" refere-se aos que empobreceram, como no caso da exceção, ou aos que não conseguiram ascender socialmente, em especial os intelectuais, o termo "degenerados" é de mais difícil compreensão. Seria necessário explorar um pouco melhor a relação do autor com as teorias raciais de sua época, o que não é o caso de se fazer aqui. No entanto, arrisco-me a dizer que "degenerados", na narrativa, significa, por um lado, a situação de desvalorização de intelectuais talentosos que o narrador atribuía ao tempo histórico da narrativa em comparação com a época de Gonçalves Dias e João Lisboa, e por outro, a degeneração social e/ou moral de uma sociedade que, hierarquicamente petrificada e atrasada, não fora mexida por dois movimentos históricos entendidos como geradores de grandes esperanças: a abolição e a república. Não é sem razão, repito, que o romance começa com a festa 
da abolição na cidade e termina em uma festa comemorativa da república, no início do século $\mathrm{XX}$, quando Cláudio - famoso, rico e comissionado - despreza as elites locais ali reunidas, gargalhando diante do convite para que falasse ao público. Ao que Zé Catraia, popular fofoqueiro ${ }^{3}$, gritou: “Fale o Paletó Queimado!” (p. 285). Paletó Queimado era a alcunha de João Machado, quitandeiro que enriqueceu trapaceando e que se adequara a sociedade local. Tendo sido protetor de João Olivier e de Cláudio, terminou, para preservar seus interesses, participando das pressões sobre o último. Diante de uma sociedade que interpusera barreiras inimagináveis à ascensão de seus talentos, somente João Machado - trapaceiro e subserviente - poderia ser ouvido. 


\section{REFERÊNCIAS}

ALMEIDA, Alfredo Wagner Berno de. A Ideologia da Decadência: Leitura antropológica a uma história da agricultura no Maranhão. Rio de Janeiro: Casa 8, Fundação Universidade do Amazonas, 2008.

BACZKO, Bronislaw. Imaginação Social. Enciclopédia Einaudi. Lisboa: Imprensa Nacional, Casa da Moeda, 1985.

BORRAlHO, José Henrique de Paula. A Athenas Equinocial: A fundação de um Maranhão no Império Brasileiro. Niterói: Universidade Federal Fluminense, Programa de Pós-graduação em História, 2009.

BOURDIEU, Pierre. Os Usos Sociais da Ciência: por uma sociologia clínica do campo científico. São Paulo: UNESP, 2004.

As Regras da Arte. 2a edição. São Paulo: Companhia das Letras, 2010.

CHIAPPINI, Ligia; AGUIAR, Flávio Wolf de. Literatura e História na América Latina. $2^{\mathrm{a}}$ edição. São Paulo: Edusp, 2001.

MACHADO, Nauro. A escrita polêmica de José do Nascimento Moraes. In: MORAES, José do Nascimento. Neurose do Medo e 100 Artigos de José do Nascimento Moraes. São Luís: Secma, Civilização Brasileira, 1982, p. 7-40.

MARTINS, Manoel Barros. Operários da Saudade: Os novos atenienses e a invenção do Maranhão. São Luís: Edufma, 2006.

MEIRELES, Mário M. Panorama da Literatura Maranhense. São Luís: s/e, s/d.

MICELI, Sérgio. Poder, sexo e letras na República Velha (estudo clínico dos Anatolianos). In: Inteligência à Brasileira. São Paulo: Companhia das Letras, 2000, p. 13-68.

MOISÉS, Massaud. Dicionário de Termos Literários. 12a edição. São Paulo: Cultrix, 2004.

MORAES, Jomar. Vida e Obra de Antônio Lobo. São Luís: Legenda, 1969. . Apontamentos de Literatura Maranhense. 3 3a edição. São Luís: Sioge, 1979. 
NASCIMENTO, Dorval do. Nosso céu não tem estrelas: O campo intelectual maranhense na Primeira República. São Paulo: Anais do XXVI Simpósio Nacional de História - ANPUH, julho 2011.

NASCIMENTO MORAES, José do. Vencidos e Degenerados. $4^{\text {a }}$ edição. São Luís: Centro Cultural Nascimento Moraes, 2000.

PÉCAUT, Daniel. Os Intelectuais e a Política no Brasil: Entre o povo e a nação. São Paulo: Ática, 1990.

RAMOS, Clóvis. Nosso Céu Tem Mais Estrelas - 140 anos de literatura maranhense. Rio de Janeiro: Pongetti, 1973.

REIS, Flávio Antonio Moura. Grupos Políticos e Estrutura Oligárquica no Maranhão (1850-1930). Dissertação. Programa de Pós-graduação em Ciência Política. Unicamp. Campinas, 1992.

PESAVENTO, Sandra. História \& Literatura: uma velha-nova história. Nuevo Mundo Mundos Nuevos, Debates, 2006. Disponível em www.nuevomundo.revues.org/1560. 
${ }^{1}$ Quando não houver outra indicação, a(s) página(s) refere(m)-se a esta edição.

${ }^{2}$ Essa característica aparece, na narrativa da fundação do grêmio, na seguinte passagem: "E, como houvesse marasmo literário no Maranhão, dormindo as letras um sono condenador, depois de tantas lutas, e tanta atividade, o Grêmio Gonçalves Dias foi uma nota saliente na vida pacata de São Luís” (p. 103).

${ }^{3} \mathrm{O}$ narrador apresenta os tipos populares, entre outras características, como dotados de sabedoria e compreensão apurada da situação social em que viviam. O conselho para Cláudio deixar a cidade e, finalmente, vencer, foi dado por seu pai, o ex-escravo Domingos Aranha (p. 276, 277). 